Research article

urn:1sid:zoobank.org:pub:0EEE6A58-B26A-4592-984D-3C2264A2AB89

\title{
A new genus of Tetracampidae (Hymenoptera) from South Africa
}

\author{
Alex GUMOVSKY ${ }^{1,2}$ \\ ${ }^{1}$ Schmalhausen Institute of Zoology, 15 Bogdan Khmelnitsky St., 01601 Kiev-30, Ukraine. \\ ${ }^{2}$ School of Animal, Plant and Environmental Sciences, University of the Witwatersrand, \\ Johannesburg, South Africa. \\ E-mails: entedon@gmail.com; gumovsky@izan.kiev.ua
}

urn:1sid:zoobank.org:author:C7B0B695-3A26-484D-A564-D6B1A6BEEDD7

\begin{abstract}
Afrocampe gen. nov. is described for its only species, A. prinslooi gen. et sp. nov., from Eastern and Western Cape, South Africa. This new genus is recognized as a member of the subfamily Tetracampinae Förster, 1856 of Tetracampidae Förster, 1856 based on the possession of 5 -segmented tarsi in females and 4-segmented tarsi in males, the short straight calcar, the mesoscutum with distinct notauli, the mesoscutellum with two pairs of setae, the reduced mesopleural suture and the short stigmal and long postmarginal veins of the fore wing. Afrocampe gen. nov. is characterized by a large mesosoma, a non-convex first gastral tergite, an evenly acute calcar, a 5-segmented antennal funicle, a head lacking occipital carina and facial grooves and a long fore wing with distinctly delimited speculum, a bare admarginal area with a distinct admarginal row of setae on the underside and with 3 setal tracks (hair rows) radiating from the apex of the stigmal vein. The combination of these characters suggests a special status of the new genus within the subfamily Tetracampinae. Moreover, Afrocampe gen. nov. bears some resemblance to the Australian tetracampine genus Niticampe Bouček, 1988. The position of the latter in Tetracampinae, as well as habitus features of the former, are discussed.
\end{abstract}

Keywords. Afrotropical, Chalcidoidea, parasitoids, new genus, taxonomy.

Gumovsky A. 2018. A new genus of Tetracampidae (Hymenoptera) from South Africa. European Journal of Taxonomy 447: 1-13. https://doi.org/10.5852/ejt.2018.447

\section{Introduction}

Tetracampidae Förster, 1856 is a relatively small family of Chalcidoidea Latreille, 1817 (Hymenoptera Linnaeus, 1758), with a complicated taxonomic history (Bouček 1958). The presently classified taxa in this family had previously been assigned to other families until Bouček (1958) proposed the current composition of Tetracampidae. The family was often reported as 'intermediate' between Pteromalidae Dalman, 1820 and Eulophidae Westwood, 1829 (Yoshimoto 1975; Bouček 1988), its contemporary diagnosis includes the possession of a short protibial spur (calcar), the antenna with at least 5 funicular segments, the mesoscutum with complete notauli and a 5-segmented tarsi in females (Noyes 2018). However, the results of recent research suggest that Tetracampidae is a polyphyletic or paraphyletic group, since its subfamilies do not form a solid clade either in trees based on molecular (Munro et al. 2011) or on combined molecular and morphological data (Heraty et al. 2013). Gumovsky (2016) 
reviewed the genera of Tetracampinae and reported the subfamily as consisting of 8 genera, 3 of which occur in the Afrotropical biogeographic realm (sensu Olson et al. 2001).

An enigmatic group of chalcidoids (Fig. 1) was discovered by the author while working with the collections of the Iziko South African Museum (Cape Town, South Africa, SAMC) and the South African National Collection of Insects, ARC-Plant Protection Research Institute (Pretoria, South Africa, SANC). Although these chalcidoids were habitually more similar to the eulophids of the subfamily Tetrastichinae (Fig. 1) rather than to any known tetracampids, the possession of the characters mentioned above unambiguously suggested their membership in Tetracampidae. The description of the genus and a discussion of its position in Chalcidoidea are provided below.

\section{Material and methods}

Color images for plates were acquired through the Leica LAS 4.4 multi-stacking imaging system in SAMC. The system included a Leica ${ }^{\circledR}$ Z16 microscope with a Leica DFC450 camera with a $0.63 \times$ video objective attached. Leica Application Suite v. 4.4 software was installed on a desk top computer to manage image acquisition using an automated Z-stepper and merging of the image series into a single in-focus image. The programs LAS v. 4.4 and Helicon Focus Pro were used to merge an image series. Scanning electron microscopy (SEM) was carried out in the Institute for Evolutionary Ecology NAS Ukraine (IEE, Kiev) using a Jeol JCM-6000 in a low-vacuum mode. Terminology largely follows that of Gibson (1997) and Heraty et al. (2013).

The following abbreviations are used:

$$
\begin{aligned}
& \text { F1-F6 }=\text { funicular segments } \\
& \text { Gt1-7 }=\text { I-VII gastral tergites } \\
& \text { MDO }=\text { major diameter of ocellus } \\
& \text { MV }=\text { marginal vein of fore wing } \\
& \text { OCL }=\text { oculo-occipital distance } \\
& \text { OOL }=\text { oculo-ocellar distance } \\
& \text { PMV }=\text { postmarginal vein of fore wing } \\
& \text { POL }=\text { post-ocellar distance } \\
& \text { SMV }=\text { submarginal vein of fore wing } \\
& \text { STV }=\text { stigmal vein of fore wing }
\end{aligned}
$$

Institutional abbreviations:

NMP $=$ National Museum, Prague, Czech Republic

SAMC $=$ Iziko South African Museum (Cape Town, South Africa)

SANC = South African National Collection of Insects, ARC-Plant Protection Research Institute (Pretoria, South Africa)

The term 'mesosoma' means the thorax and propodeum together, and 'metasoma' is a complex of petiole and gaster (Gibson 1997; Heraty et al. 2013). 

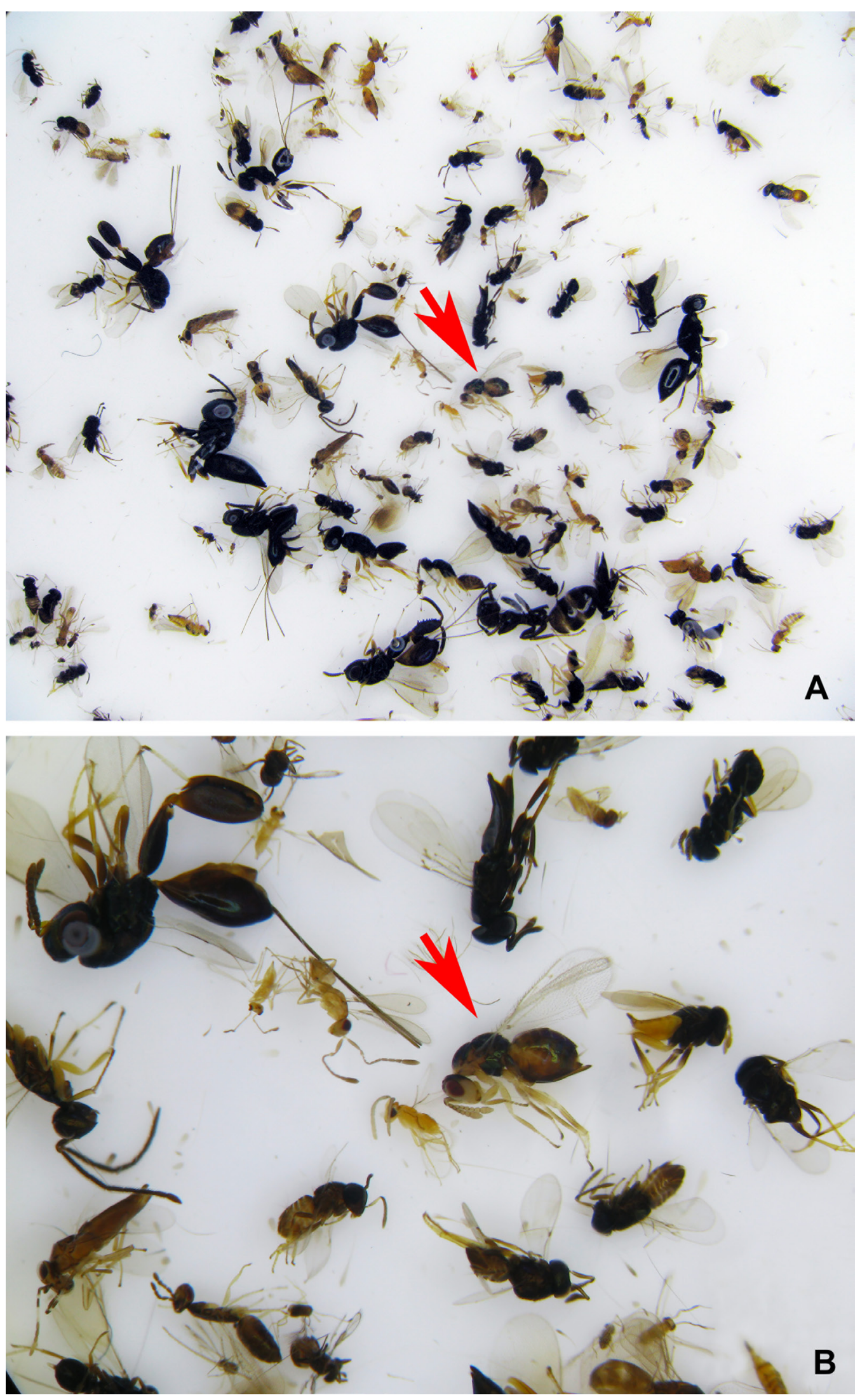

Fig. 1. Afrocampe prinslooi gen. et sp. nov., paratype (arrows),, , in a sample from the Grootvadersbosch Nature Reserve (Western Cape, South Africa) among other chalcidoid wasps. A-B. General view. 


\title{
Results
}

Class Insecta Linnaeus, 1758

Order Hymenoptera Linnaeus, 1758

Superfamily Chalcidoidea Latreille, 1817

Family Tetracampidae Förster, 1856

Subfamily Tetracampinae Förster, 1856

\author{
Afrocampe gen. nov. \\ urn:lsid:zoobank.org:act:724B1276-8B4C-47B3-8191-2D15F2C56387
}

Figs 1-4

\section{Type species}

Afrocampe prinslooi gen. et sp. nov., by present designation and monotypy.

\section{Diagnosis}

Foretibial spur (calcar) short and evenly acute, tarsi 5-segmented in female (Fig. 2A), 4-segmented in male (Fig. 4D), antennal funicle 5-segmented in both sexes (Figs 2B, 3A, D-E, 4E), head lacking facial grooves (Fig. 2B) and occipital carina (Fig. 2D), mesoscutum with complete notauli (Fig. 2D, F), mesoscutellum with two pairs of setae (Figs 2F, 3B), fore wing poorly setose basally, its disc and speculum distinctly delimited, admarginal row of setae distinct and situated on underside of bare area along MV, PMV about $3.0 \times$ as long as short STV, with 3 hair rows radiating from it (Figs 2A, C, E, 4A, C); Gt1 not swollen (Figs 1B, 2A, 4A).

\section{Etymology}

The specific epithet is a combination of Afro- (reflecting the Afrotropical distribution of the genus) and -campe (from Tetracampe). Gender feminine.

\section{Description}

Body with ovoid head (Fig. 2B), robust mesosoma (Fig. 3A, D) and relatively short metasoma (Figs 2A, 4A); eyes sparsely setose (Figs 2B, D, 3E); flagellum with one anellus (bearing a short seta in the holotype: Fig. 3G, arrow), 5-segmented funicle and 3-segmented club, apex of which evenly rounded (Figs 2B, $3 \mathrm{~A}, \mathrm{E})$; face with light sculpture, nearly smooth, with scrobal area sunken into median margined cavity, without facial grooves (Fig. 2B); anterior margin of clypeus slightly produced and weakly notched medially (Fig. 3F). Occiput not margined, occipital carina missing (Fig. 2D, F). Pronotum large, conical, its collum evenly sloping (Figs 2D, 3A). Vertex and pronotum with sparse bristles (Fig. 2D, F), midlobe of mesoscutum with distinct straight notauli and three pairs of strong bristles (Fig. 2D); mesoscutellum with two pairs of strong bristles, frenal area not distinctly marked off (but somewhat smoother than rest of scutellum in A. prinslooi gen. et sp. nov., Fig. 2F). Propodeum relatively transverse, its submedian areas entirely smooth and bare; spiracles small and round, closely adjacent to metanotal margin (Figs 2F; 3B-C). Tarsi of all legs 5-segmented in female (Figs 2A, 4A), 4-segmented in male (Fig. 4D). Each leg with one evenly acute spur. Basic part of fore wing poorly setose, with some strong bristles, SMV not broken; with 5 dorsal bristles, wing disc and speculum distinctly delimited by membrane folds and hair rows; admarginal area bare, with a row of setae at underside; PMV long, about $3.0 \times$ as long as short STV, from which 3 hair rows radiate (Fig. 4C). Petiole rather transverse (Fig. 3C). Metasoma about as long as mesosoma, female gaster ovate (Figs 2E, 3B-C, 4A); Gt1 not swollen, not more convex than following tergites (Figs 1B, 4A), posterior margins of Gt2-5 straight (Fig. 3B-C); syntergum short, 

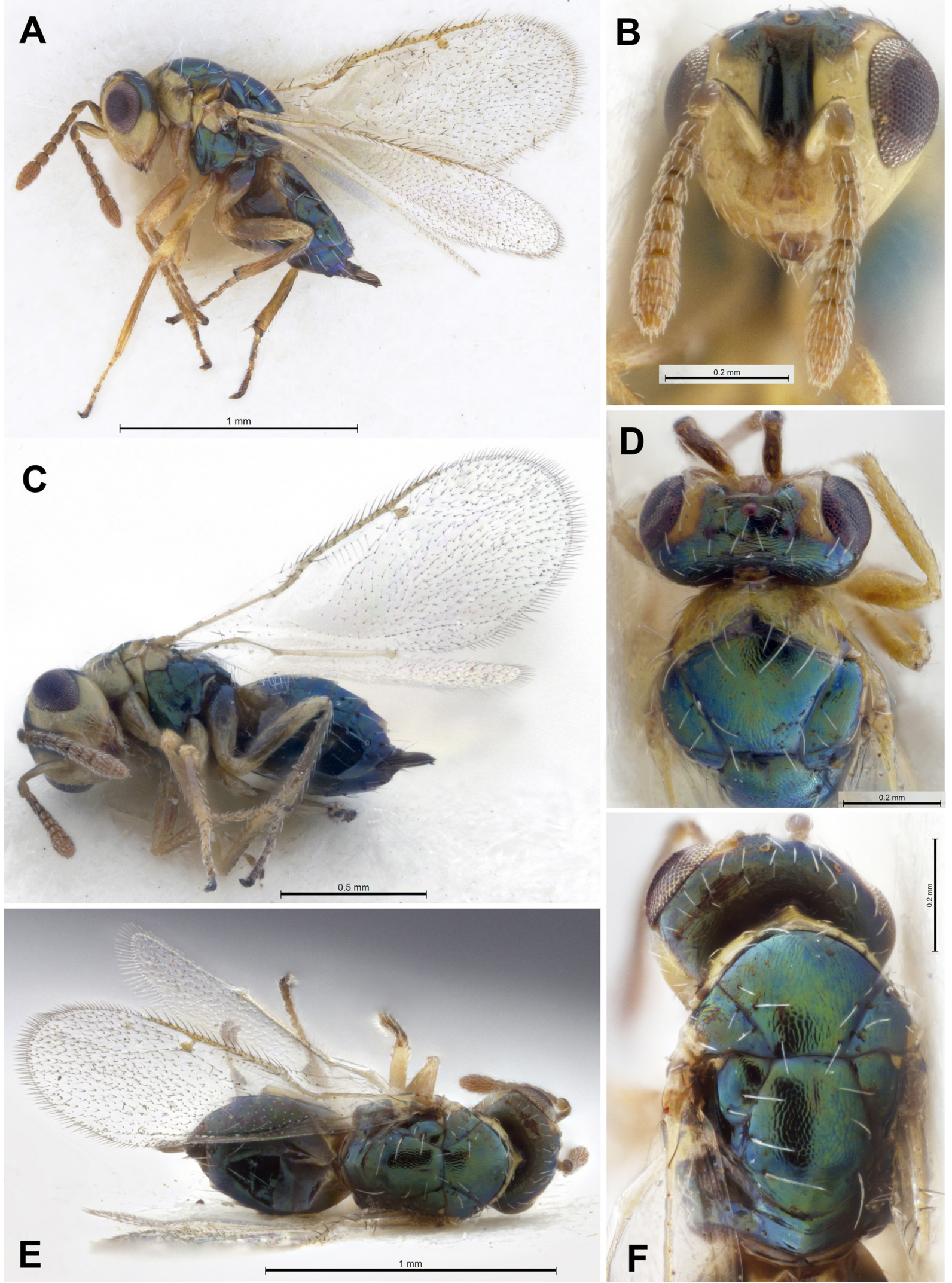

Fig. 2. Afrocampe prinslooi gen. et sp. nov., holotype (color imaging), ${ }$. A. Habitus in lateral view. B. Face. C. Habitus in ventro-lateral view. D. Head and anterior part of mesosoma. E. Habitus in dorsal view. F. Head and mesosoma in dorsal view. 

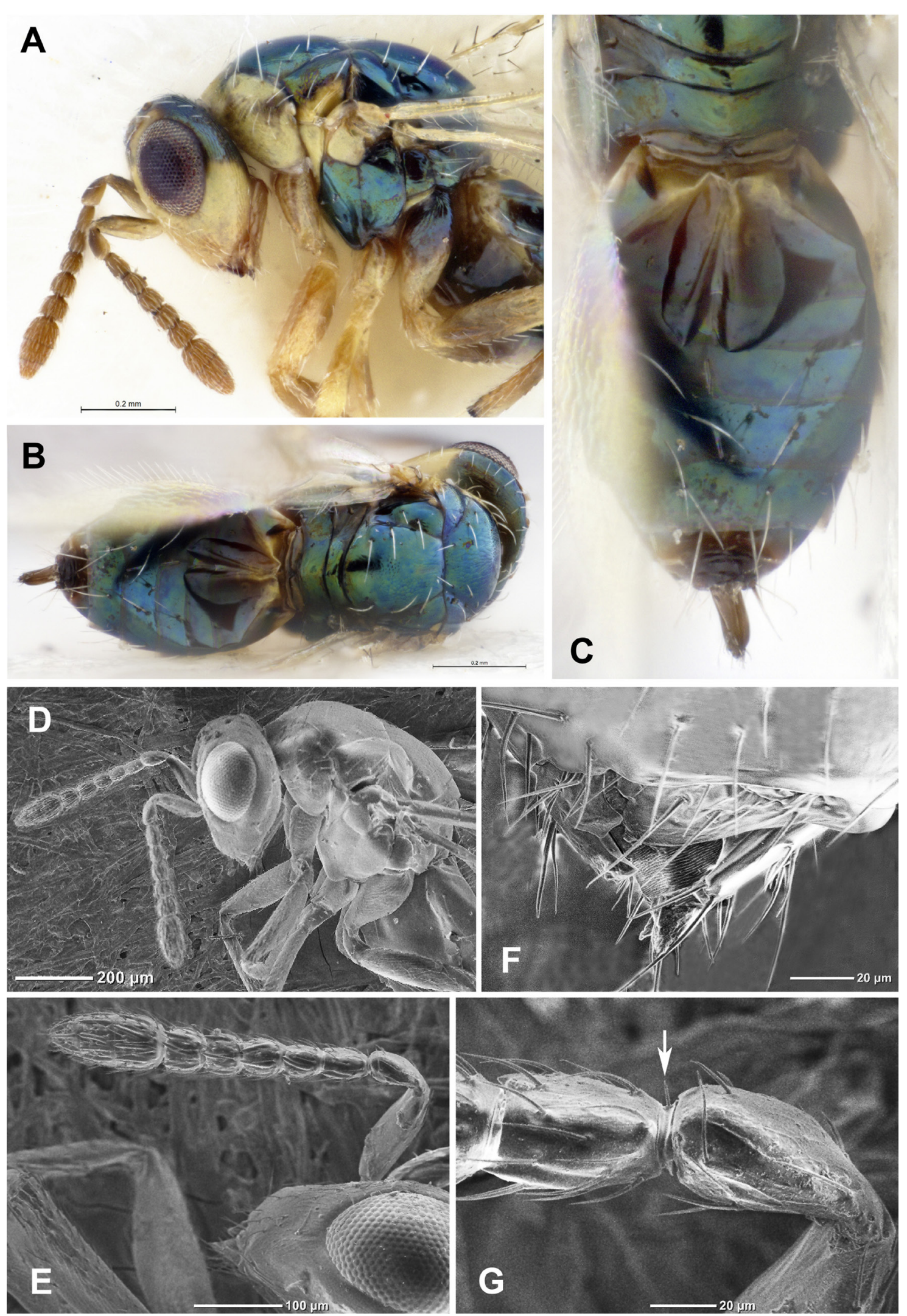

Fig. 3. Afrocampe prinslooi gen. et sp. nov., holotype, $q$. A, D. Head and mesosoma in lateral view. B. Body in dorsal view. C. Metasoma and posterior part of mesosoma. E. Antenna. F. Mouth opening and clypeus. G. Pedicel, anellus and F1 (seta on anellus is arrowed). A-C = color imaging; D-G = SEM. 

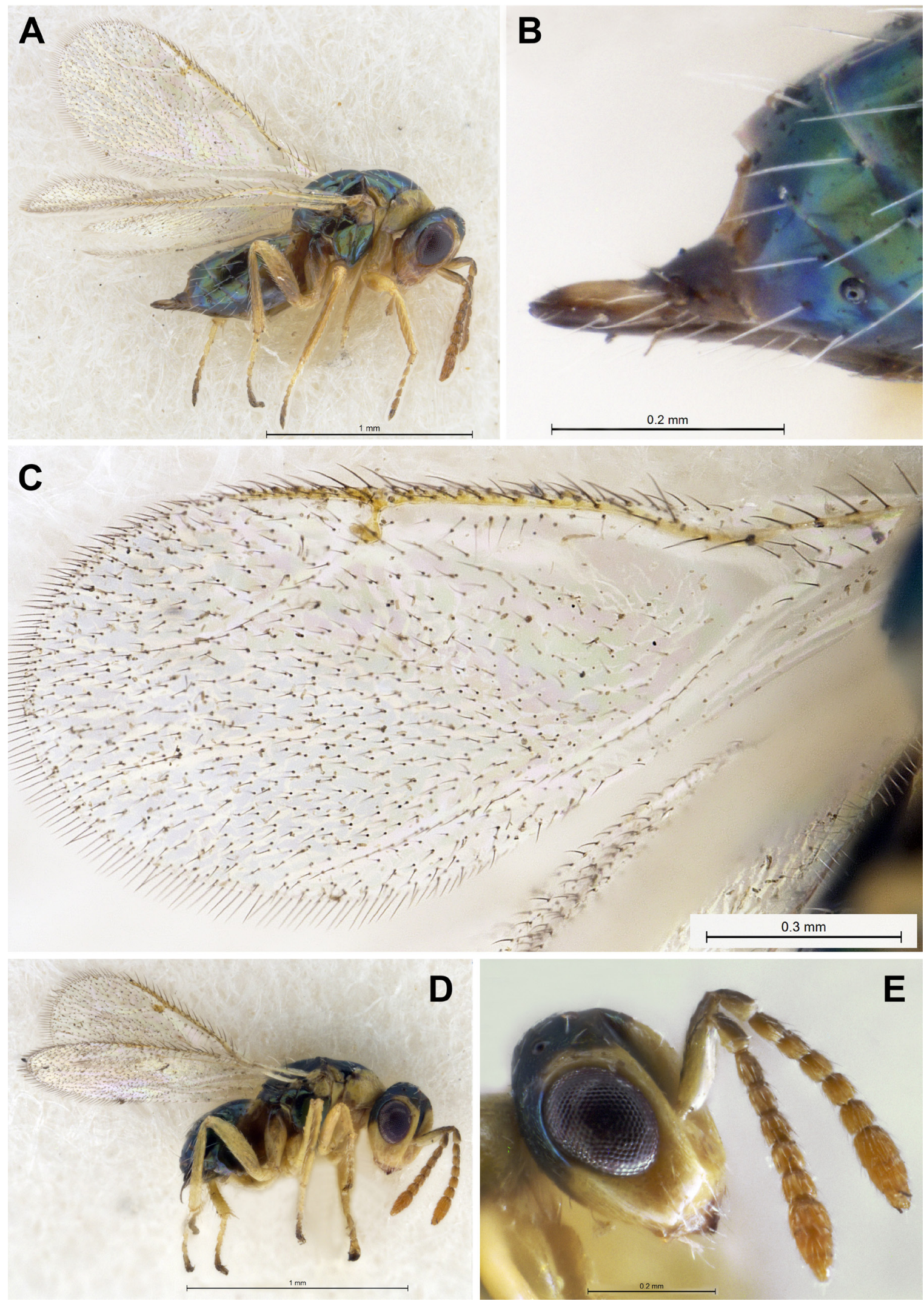

Fig. 4. Afrocampe prinslooi gen. et sp. nov. (color imaging). A-C. Paratype,, , from Baviaanskloof. D-E. Paratype, ${ }^{\lambda}$, from Baviaanskloof. A, D. Habitus in lateral view. B. Tip of gaster. C. Fore wing. E. Head. 
with membranous apical tip (Figs 3C, 4B); ovipositor sheaths short, but protruding (Figs 3C, 4B); hypopygium not reaching apex of metasoma, mucro short.

\section{Comparative notes}

The new genus is very different from all known chalcidoids, but may be assigned to the subfamily Tetracampinae of the family Tetracampidae as judged chiefly from the combination of the 5-segmented tarsi in females, the 4-segmented tarsi of males and the short straight calcar (see Discussion). Afrocampe gen. nov. has some characters in common with Niticampe Bouček, 1988: the reduced occipital carina, the missing frontal grooves, the evenly acute calcar, the flat Gt1, the poorly setose base of the fore wing and the distinct forewing speculum. However, Afrocampe gen. nov. differs from Niticampe in general habitus, with a large convex mesosoma (slender in Niticampe), the 5-segmented antennal funicle (6-segmented in Niticampe) and by the setation of the forewing disc (see Discussion).

\section{Biology}

Not known.

\section{Distribution}

Afrotropical realm (Cape floristic region).

Afrocampe prinslooi gen. et sp. nov. urn:1sid:zoobank.org:act:8E28E6F6-88FE-46C1-94EA-A79D903D1FF0

Figs $1-4$

\section{Etymology}

The species is named after Gerhard Prinsloo, a famous expert on South African Chalcidoidea, who collected part of the type series and also first noticed and sorted out the SANC specimens as unusual tetracampids.

\section{Material examined}

\section{Holotype}

SOUTH AFRICA: + , Bathhurst, C.P., Jan. 1979, G.L. Prinsloo leg. (deposited in SANC).

\section{Paratypes}

SOUTH AFRICA: 1 + , Bathurst, C.P., Jan. 1979, G.L. Prinsloo leg., National Coll. of Insects, Pretoria, S. Afr. (NMP); 2 우, Nieu Bethesda, Feb. 1990, G.L. Prinsloo leg., National Coll. of Insects, Pretoria,

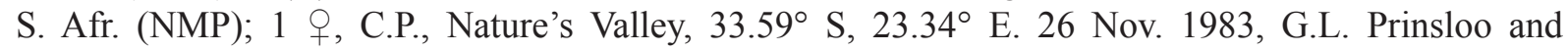
N.C. Grobbelaar leg., National Coll. of Insects, Pretoria, S. Afr. (NMP); 1 o, C.P., Knysna, $34.02^{\circ}$ S, $23.03^{\circ}$ E. 26 Nov. 1983, G.L. Prinsloo and N.C. Grobbelaar leg., National Coll. of Insects, Pretoria, S. Afr. (NMP); 2 우, 1 ô, C.P., Baviaanskloof, 23-24 Nov. 1983, G.L. Prinsloo and N.C. Grobbelaar leg. (SANC); 1 q, Grahamstown, C.P., Jan. 1979, G.L. Prinsloo leg. (SANC); 1 ○े (headless), C.P., Humansdorp, $34.02^{\circ}$ S, $24.46^{\circ}$ E, 27 Nov. 1983, G.L. Prinsloo and N.C. Grobbelaar leg. (SANC); 1 ,

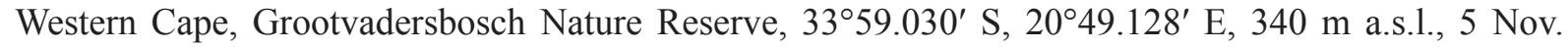
2009-27 Feb. 2010, Malaise trap, afromontane forest, S. van Noort leg. (GVB10-FOR1-M01, SAMHYM-P067822) (SAMC); 1 o, Eastern Cape, Winterberg, the Hoek farm, 32 $21.260^{\prime}$ S, $26^{\circ} 23.001^{\prime}$ E, 1879 m a.s.1., 26 Jul.-6 Oct. 2010, yellow pan trap, Amathole mistbelt grassland, S. van Noort leg. (WTB09-GRA1-Y05, SAM-HYM-P067823) (SAMC).

\section{Description}

Female

LeNGTH. 1.4-1.6 mm. 
Colour. Body with yellow and blue-green markings: head mostly yellow apart from black scrobal depression and green metallic occiput and vertex; meso- and metasoma mostly metallic green, except for yellow pronotum, prepectus, acropleuron, tegulae and shoulders of mesoscutum; legs and antennae yellow-brown, except for green metallic anterior parts of hind coxae and black pretarsi (Figs 2, 3A-C, 4A-B). Wings transparent, veins pale brown, dorsal bristles pale (Fig. 4C).

HEAD. In dorsal view about $2.0 \times$ as long as broad, vertex smoothly transits to occiput, so occipital margin not traceable (Fig. 2D). POL about $2.0 \times$ OOL, OOL about $2.3 \times$ MDO. Head in frontal view $1.2 \times$ as wide as high; eye approximately $2.3 \times$ as high as broad; ventral margin of torulus situated slightly above virtual line connecting lower margins of eye orbits (Fig. 2B). Minimum distance between inner orbits about $0.6 \times$ width of head. Face smooth, width of scrobal depression about $0.3 \times$ that of face (Fig. 2B). Mouth opening about $1.3 \times$ as wide as malar space (malar space about $0.7-0.8 \times$ as long as mouth opening, Fig. 3F). Inner margins of eyes slightly diverging. Genae nearly straight. Mandibles oriented downwards, bidentate (Fig. 3F). Malar suture sulcate, complete. Antenna (Fig. 3E) with scape about $4.8 \times$ as long as wide, pedicel $1.7 \times$ as long as broad. F1 1.5-1.6 $\times$ as long as broad, F2 $1.2 \times$ as long as broad, F3 $1.3 \times$ as long as broad, F4 and F5 slightly longer than wide, club slightly more than $2.0 \times$ as long as broad, club $3.0 \times$ as long as F5, its segments separated by sutures, terminal spine very short.

Mesosoma. About $1.5 \times$ as long as broad, weakly alutaceous (Fig. 2D-F). Pronotum short, conical, about $0.2 \times$ as long as mesoscutum. Mesoscutum about $1.8 \times$ as broad as long; mesoscutellum slightly wider than long and slightly longer than mesoscutum, with 2 pairs of strong bristles, its surface alutaceous, posterior $1 / 4$ smoother (Fig. 2D-F). Axilla with two strong bristles. Mesopleuron smooth and flat, mesopleural suture present as a very shallow groove (Fig. 3A, D). Propodeum as narrow stripe, smooth, without sculpture (Fig. 3C), its callus with 10 setae.

Metanotum. With relatively wide, smooth dorsellum, about $0.15 \times$ as long as mesoscutellum (Fig. 3C). Metapleuron subrectangular, with alutaceous sculpture, nearly flat (Fig. 3A, D).

Fore WING. Approximately $2.4-2.5 \times$ as long as broad (Fig. 4C), slightly longer than body (Figs 2A, C, E, 4A). Subcosta of SMV tapering, but not broken when transiting to parastigma, with 5 dorsal bristles (Fig. 4C), MV slightly longer (about $1.1 \times$ ) than costal cell, about $0.6 \times$ wing width, STV with short petiole, nearly perpendicular to MV, with subtriangular or spherical stigma and short, relatively wide uncus, PMV about 3.4-3.8 $\times$ as long as STV (Fig. 4C). Marginal fringe long, as long as STV, about $2.0-2.5 \times$ as long as width of MV at its broadest part (Fig. 4C).

LEG. Front leg with a short calcar, about as long as width of its tibia, evenly acute and nearly straight; midtibial spur about $2.0 \times$ as long as width of its tibia; hindtibial spur $1.2 \times$ as long as width of its tibia.

Metasoma. 1.1-1.2 $\times$ as long as mesosoma (Figs 2A, E, 4A); petiole rather transverse, lightly sculptured (Figs 2A, C, E, 4A). Gaster about $1.5 \times$ as long as wide in dorsal view (Fig. 3B-C). Gt2-5 with posterior margins straight (Fig. 3C); Gt6 nearly straight posteriorly, bearing gastral spiracles (Figs 3C, 4B); syntergum with a pair of short cerci (each with three long, straight setae) and with a membranous lobe at its posterior end (Figs 3C, 4B).

\section{Male}

Length about $0.9 \mathrm{~mm}$. Very similar to female (Fig. 4D), but with somewhat longer flagellar segments (Fig. 4E), 4-segmented tarsi and shorter gaster.

\section{Biology}

Unknown. 


\section{Distribution}

South Africa: Eastern and Western Cape.

\section{Discussion}

Afrocampe gen. nov. is considered here a member of the family Tetracampidae based on the possession of the characters traditionally used to distinguish the family (Bouček 1958, 1988; Gibson et al. 1997; Gumovsky 2016): the short, straight calcar, the 5-segmented tarsus of the female and the mesoscutellum with two pairs of bristles. Heraty et al. (2013) and Gumovsky (2016) suggested that the other extant and fossil groups assigned to this family are likely not related to the nominal subfamily Tetracampinae. Heraty et al. (2013) reported Tetracampinae as monophyletic based on 6 synapomorphies. However, none of these character states are present in Afrocampe gen. nov. Indeed, the male antenna possesses 5 funicular segments in the new genus (not 6 , as in most Tetracampinae), the head lacks the upper ocular and transfacial sulci (present in most Tetracampinae), the clypeus is not inflected into the oral cavity (more or less inflected in most Tetracampinae), and the forewing speculum is distinctly delimited (not delimited in most Tetracampinae). The presence of an isolated large bristle on each posterolateral corner of the pronotum (as in other tetracampines) is questionable in Afrocampe gen. nov., because in $A$. prinslooi gen. et sp. nov. the setae in that area are hardly distinguishable from the other dorsal pronotal setae. Gumovsky (2016) listed a number of characters that are diagnostic for Tetracampinae, 5 of which are also present in Afrocampe gen. nov.: 1) the short, straight calcar, 2) the 5-segmented female tarsus, 3) the mesoscutellum with two pairs of setae, 4) the mesopleural suture scarcely evident and 5) the short STV and long PMV. However, the new genus does not possess 5 of the other diagnostic characters for the subfamily, namely: 1) the complete occipital carina, 2) the distinct V-shaped frontal sulcus, 3) the swollen Gt1, 4) the densely setose base of fore wing and 5) the 6-segmented antennal funicle. These characters, apart from the latter, are also absent in the Australian genus Niticampe, which may suggest a relationship with Afrocampe gen. nov. Furthermore, both Niticampe and Afrocampe gen. nov. possess an evenly acute calcar (foretibial spur), as in representatives of the subfamily Mongolocampinae Sugonjaev, 1971 of Tetracampidae, whereas the calcar is bifid in other tetracampines. However, Niticampe has a 6-segmented antennal funicle, which suggests its affinity with Tetracampinae, whereas the funicle is distinctly 5-segmented in Afrocampe gen. nov., unlike most other known tetracampines. The 5-segmented funicle is also shared with Mongolocampinae. Also, the fore wing of Afrocampe gen. nov. bears a distinct admarginal hair row on the underside and hair rows which radiate from STV (Fig. 4C, as in the genus Euderus Haliday, 1844 of Eulophidae). Such a forewing setation is not represented in any of the currently described tetracampines. The habitus of Afrocampe gen. nov. is very unusual for Tetracampidae. The robust mesosoma and long fore wing (Figs 2A, C, 4A) differentiate A. prinslooi gen. et sp. nov. from other tetracampids. The combination of a yellow and metallic green colouration is also uncommon among tetracampids, apart from the members of Mongolocampinae, with which Afrocampe gen. nov. also shares the evenly acute calcar and an antenna with one anellus and 5-segmented funicle, but differs in the structure of the mesosoma and forewing venation.

All the above-mentioned considerations make a subfamily attribution problematic for Afrocampe gen. nov. However, it is regarded here as a representative of Tetracampinae, based on the following considerations. First, Afrocampe gen. nov. shares dimorphism in its tarsomere count (5-segmented tarsi of females, 4-segmented of males) with other Tetracampinae. The tarsomere dimorphism does not occur in other Tetracampidae, and may also be considered a putative synapomorphy of the subfamily, even though it was not treated prominently enough in recent phylogenetic studies (Heraty et al. 2013). Second, the 5-segmented funicle is very rare, but not entirely unique for Tetracampinae: it was recorded for Foersterella scaposa Bouček, 1988 (Bouček 1988). Third, Afrocampe gen. nov. shares many derived characters with the genus Niticampe, which is, however, characterized by a 6-segmented antennal funicle, similar to most other tetracampines. Both genera are also characterized 
by an evenly acute, non-bifid calcar and may represent a derived cluster within Tetracampinae. The Cape floristic region of South Africa is characterized by a high level of regional and local endemism (Cowling \& Holmes 1992; Cowling et al. 1996). The type series of Afrocampe gen. nov. is restricted to this region: despite rigorous and thorough surveys of museum collections and numerous samples collected by the author in Africa, no additional specimens of $A$. prinslooi gen. et sp. nov. were recorded outside the Eastern and Western Cape Provinces. Such a restricted distribution suggests that Afrocampe gen. nov. is endemic to this region.

When observed among other chalcidoids in a sample (Fig. 1), a specimen of A.prinslooi gen. et sp. nov. is habitually reminiscent of many representatives of the subfamily Tetrastichinae of Eulophidae. The most remarkable similarity in color and body shape is reminiscent of the species of the genera Aprostocetus Westwood, 1833 and Sigmophora Rondani, 1867, which are often associated with galls, in their turn, either as parasitoids or as gall-formers (Noyes 2018). Interestingly, the representatives of the abovementioned subfamily Mongolocampinae, with which Afrocampe gen. nov. shares the structure of the calcar and antennae, are also reported to be either gall formers or gall-former parasitoids (Sugonjaev \& Voinovich 2003). Though habitual appearance is not a reliable signal of host association, one can hypothesize that $A$. prinslooi gen. et sp. nov. is also a gall associate, as in mongolocampines or some tetrastichines. Therefore, a survey for the host of Afrocampe gen. nov. should target the gall formers on endemic plants of the Cape floristic region.

\section{Acknowledgements}

This paper represents a section of the revisionary research on Afrotropical Tetracampidae, being a part of the author's project supported by the Belgian Science Policy (BELSPO), the Marie-Curie Actions and the German Academic Exchange Service (DAAD) and is a contribution towards the Afrotropical Hymenoptera Initiative driven by Simon van Noort (SAMC). The author thanks Isabel M. Weiersbye (Ecological Engineering and Phytotechnology Programme in the School of APES, University of the Witwatersrand, Johannesburg) for general assistance and support during work in South Africa, Vladimir Radchenko for useful advice and access to SEM in IEE, Ros Urban and Cornelis A. du Toit for their help with the SANC collection and Simon van Noort and Aisha Mayekiso for access to the SAMC collection and invaluable assistance during the stay at the SAMC IZIKO museum, Jan Macek (NMP) and Petr Janšta (Charles University, Prague, Czech Republic) for their help while working in their institutions. The author's visits to SANC were supported by THRIP (Department of Trade \& Industry and National Research Foundation of South Africa) grant TP13080525596, and the visit to SAMC was supported by the South African National Research Foundation grant GUN 98115 awarded to Simon van Noort and NSF DEB 1555808 to John Heraty. The author also appreciates the constructive criticism and valuable suggestions of two anonymous reviewers of the manuscript.

\section{References}

Bouček Z. 1958. Revision der europäischen Tetracampidae (Hym. Chalcidoidea) mit einem Katalog der Arten der Welt. Acta Entomologica Musei Nationalis Pragae 32: 41-90.

Bouček Z. 1988. Australasian Chalcidoidea (Hymenoptera). A Biosystematic Revision of Genera of fourteen Families, with a Reclassification of Species. CAB International, Wallingford, Oxon, UK and Cambrian News Ltd, Aberystwyth, Wales, UK.

Cowling R.M. \& Holmes P.M. 1992. Endemism and speciation in a lowland flora from the Cape Floristic Region. Botanical Journal of the Linnean Society 47: 367-383.

https://doi.org/10.1111/j.1095-8312.1992.tb00675.x 
Cowling R.M., MacDonald I.A.W. \& Simmons M.T. 1996. The Cape Peninsula, South Africa: physiographical, biological and historical background to an extraordinary hot-spot of biodiversity. Biodiversity and Conservation 5: 527-550. https://doi.org/10.1007/BF00137608

Gibson G. 1997. Morphology and terminology. In: Gibson G.A.P, Huber J.T. \& Woolley J.B. (eds) Annotated Keys to the Genera of Nearctic Chalcidoidea (Hymenoptera): 16-44. NRC Research Press, Ottawa, Ontario, Canada.

Gumovsky A. 2016. A review of genera and described Afrotropical species of Tetracampinae (Hymenoptera: Tetracampidae), with description of a new genus from East Central Africa. Zootaxa 4111 (4): 393-420. https://doi.org/10.11646/zootaxa.4111.4.4

Heraty J.M., Burks R.A., Cruaud A., Gibson G.A.P., Liljeblad J., Munro J., Rasplus J.-Y., Delvare G., Jansta P., Gumovsky A., Huber J., Woolley J.B., Krogmann L., Heydon S., Polaszek A., Schmidt S., Darling D.C., Gates M.E., Mottern J., Murray E., DalMolin A., Triapitsyn S., Baur H., Pinto J.D., van Noort S., George J. \& Yoder M.A. 2013. A phylogenetic analysis of the megadiverse Chalcidoidea (Hymenoptera). Cladistics 29: 466-542. https://doi.org/10.1111/cla.12006

Munro J.B., Heraty J.M., Burks R.A., Hawks D., Mottern J., Cruaud A., Rasplus J.-Y. \& Jansta P. 2011. A molecular phylogeny of the Chalcidoidea (Hymenoptera). PLoS ONE 6 (11): e27023. https://doi.org/10.1371/journal.pone.0027023

Noyes J.S. 2018. Universal Chalcidoidea Database. WWW publication, the Natural History Museum, London.

Available from http://www.nhm.ac.uk/research-curation/projects/chalcidoids/index.html [accessed 10 Jan. 2018].

Olson D.M., Dinerstein E., Wikramanayake E.D., Burgess N.D., Powell G.V.N., Underwood E.C., D'amico J.A., Itoua I., Strand H.E., Morrison J.C., Loucks C.J., Allnutt T.F., Ricketts T.H., Kura Y., Lamoreux J.F., Wettengel W.W., Hedao P. \& Kassem K.R. 2001. Terrestrial ecoregions of the World: a New Map of Life on Earth: a new global map of terrestrial ecoregions provides an innovative tool for conserving biodiversity. BioScience 51 (11): 933-938.

https://doi.org/10.1641/0006-3568(2001)051[0933:TEOTWA]2.0.CO;2

Sugonjaev E.S. \& Voinovich N.D. 2003. On the geographic distribution and host linkages of phytophagous chalcids of the subfamily Mongolocampinae (Hymenoptera, Chalcidoidea, Tetracampidae) living on Nitraria spp. (Nitrariaceae), with descriptions of their immature stages. Entomologicheskoe Obozrenie 82 (2): 310-320, 529.

Yoshimoto C.M. 1975. Cretaceous chalcidoid fossils from Canadian amber. The Canadian Entomologist 107: 499-528. https://doi.org/10.4039/Ent107499-5

Manuscript received: 8 November 2017

Manuscript accepted: 22 January 2018

Published on: 26 June 2018

Topic editor: Gavin Broad

Desk editor: Kristiaan Hoedemakers

Printed versions of all papers are also deposited in the libraries of the institutes that are members of the EJT consortium: Muséum national d'Histoire naturelle, Paris, France; Botanic Garden Meise, Belgium; Royal Museum for Central Africa, Tervuren, Belgium; Natural History Museum, London, United Kingdom; Royal Belgian Institute of Natural Sciences, Brussels, Belgium; Natural History Museum 
of Denmark, Copenhagen, Denmark; Naturalis Biodiversity Center, Leiden, the Netherlands; Museo Nacional de Ciencias Naturales-CSIC, Madrid, Spain; Real Jardín Botánico de Madrid CSIC, Spain; Zoological Research Museum Alexander Koenig, Bonn, Germany. 